\title{
Discontinuation of hormone replacement therapy after myocardial infarction and short term risk of adverse cardiovascular events: nationwide cohort study
}

\author{
(c) $\frac{(1)(8)}{\text { gy }}$ OPEN ACCESS
}

\author{
Ditte-Marie Bretler research fellow ${ }^{1}$, Peter Riis Hansen consultant cardiologist ${ }^{1}$, Rikke Sørensen \\ research fellow ${ }^{2}$, Jesper Lindhardsen research fellow ${ }^{1}$, Ole Ahlehoff research fellow ${ }^{1}$, Charlotte \\ Andersson research fellow ${ }^{1}$, Steen Zabell Abildstrøm consultant cardiologist ${ }^{2}$, Christian \\ Torp-Pedersen professor ${ }^{13}$, Gunnar Hilmar Gislason consultant cardiologist ${ }^{1}$
}

${ }^{1}$ Department of Cardiology, Copenhagen University Hospital Gentofte, Copenhagen, Denmark; ${ }^{2}$ Department of Cardiology, Copenhagen University Hospital Bispebjerg, Copenhagen; ${ }^{3}$ Faculty of Health Sciences, Panum Institute, University of Copenhagen, Copenhagen

\begin{abstract}
Objective To assess the risk of adverse cardiovascular events in women who discontinue hormone replacement therapy after myocardial infarction compared with those who continue.

Design Nationwide register based cohort study.

Setting All hospitals in Denmark.

Population All 3322 women aged 40 years or over who survived 30 days after a myocardial infarction and were prescribed hormone replacement therapy at the time of myocardial infarction in the period 1997 to 2008.
\end{abstract}

Main outcome measures Reinfarction, cardiovascular mortality, and all cause mortality 30 to 360 days after discharge.

Results A total of 282 (8.5\%) women had a reinfarction, 218 (6.6\%) died of cardiovascular causes, and 357 (10.7\%) died of any cause during follow-up. Women who discontinued overall hormone replacement therapy in the first year after myocardial infarction did not have a significantly different risk of reinfarction (hazard ratio $0.90,95 \%$ confidence interval 0.68 to 1.19$)$, cardiovascular mortality $(1.21,0.90$ to $1.62)$, or all cause mortality $(1.22,0.97$ to 1.53$)$ than women who continued use. However, discontinuation of vaginal oestrogen was associated with a lower risk of reinfarction (hazard ratio $0.54,0.34$ to 0.86).

Conclusion No certain conclusions can be drawn regarding increased or decreased risk of adverse cardiovascular events with continuing hormone replacement therapy after myocardial infarction. The results rule out neither a modest benefit nor a worrisome increase in risk. These figures may be valuable when a possible cardiovascular risk of hormone replacement therapy needs to be balanced with menopausal symptoms for the individual patient.

\section{Introduction}

Hormone replacement therapy (HRT) was recommended for prevention of coronary artery disease until the end of the $1990 \mathrm{~s}$ because several observational studies had shown a cardioprotective effect of HRT ${ }^{1-3}$ However, in 1998 the Heart and Estrogen Replacement Study evaluated the role of HRT compared with placebo for secondary prevention of coronary artery disease and found no significant differences in the primary outcome of cardiac death or myocardial infarction, and in 2001 the Women's Health Initiative study of HRT for primary prevention was stopped prematurely when an increased risk of coronary artery disease in women using HRT was found. ${ }^{45}$ As a result, guidelines now recommend that HRT should not be used for primary or secondary prevention of coronary artery disease. $^{6-8}$

Oestrogen has favourable effects on endothelial function, as well as inflammatory and haemostatic mechanisms. ${ }^{9}$ However, these effects and the blood concentrations of respective hormones differ between different types of HRT and routes of administration, and they disappear rapidly after discontinuation of HRT. ${ }^{10-17}$ Discontinuation of HRT can be troublesome owing to rebound climacteric symptoms, and this is particularly problematic in women diagnosed as having coronary artery disease while using HRT, as guidelines for this situation recommend discontinuation of HRT although evidence on the risk-benefit of this strategy is lacking. ${ }^{18-21}$ Indeed, the period after a myocardial infarction is a pathophysiologically vulnerable time, with endothelial dysfunction, elevated inflammatory markers, and so on, and potential rebound effects on these mechanisms of discontinuation of HRT may be more prone to cause adverse cardiovascular events in this period. ${ }^{22-24} \mathrm{We}$ have 
previously shown that in spite of current recommendations for discontinuation of HRT after myocardial infarction, around $80 \%$ of women in Denmark using HRT at the time of myocardial infarction continue HRT after discharge. ${ }^{25}$

The aim of this study was therefore to assess whether women who discontinue HRT after myocardial infarction have a lower risk of reinfarction, cardiovascular death, or all cause death in the first year after myocardial infarction than do women who continue HRT.

\section{Methods}

All citizens in Denmark have a unique civil registration number that enables linkage of nationwide registers at an individual level. The Danish national patient register holds information on all admissions to Danish hospitals since 1978 registered by diagnoses according to the World Health Organization's international classification of diseases (ICD). Operations are classified according to the Danish classification of operation until 1996 and according to the Nordic Medico-Statistical Committee's classification of surgical procedures from 1997. ${ }^{26}$ The Danish national prescription register holds information on all prescriptions dispensed by Danish pharmacies since 1995. Prescriptions are coded according to the anatomic therapeutical chemical (ATC) system. All residents in Denmark are covered by a national health security system and have the cost of drugs partially reimbursed. ${ }^{27}$ All pharmacies are therefore required to register all dispensed prescriptions. All deaths are registered in the central population register within 14 days of occurrence.

\section{Population}

We identified all women who were aged 40 years or older on 1 January 1997 and discharged with a diagnosis of myocardial infarction (ICD-8 code 410, ICD-10 codes I21 to I22) in the period 1997 to 2008 in the national patient register. The diagnosis of myocardial infarction in this register has previously been validated and has a sensitivity of $91 \%$ and a positive predictive value of $93 \% .{ }^{28} \mathrm{We}$ included women who were still alive 30 days after discharge (fig $1 \Downarrow$ ). As a measure of socioeconomic status, we calculated the yearly household income as an average of the income in the five years before admission, where possible, and divided it into thirds of income. We excluded all women who migrated to or from Denmark in the study period 1997 to 2008 .

\section{Use of hormone replacement therapy}

We identified all claimed prescriptions for HRT in the Danish register of medicinal product statistics (ATC codes G03C, G03D, G03F, G03XC and G02BA03) in the study period. We did not include drugs usually used for contraceptive purposes, except for a progesterone intrauterine device which is commonly used by postmenopausal women. HRT covers a broad spectrum of chemical compounds, formulations, routes of administration, and dosages. We divided this pharmacological multiplicity into four categories (table $1 \Downarrow$ ): oestrogen alone, combinations of oestrogen and progestogen, vaginal oestrogen alone, and "other HRT." These categories were mutually exclusive. We used the "other HRT" category to ensure that all treatment intervals could be included in the analyses, not because of similarities of the treatments in this group.

The register includes information about dispensing date, strength, and quantity of the prescription. Indication and daily drug dosage are not included in the register, so we estimated the daily drug dose by calculating the average drug dose of up to three consecutive prescriptions before the actual prescription and not using information on future prescriptions in the calculations. This method has previously been described in detail. ${ }^{29}$ On the basis of these assumptions, we calculated periods when HRT was available and we defined patients as receiving HRT if it was available. Similarly, we defined discontinuation of any of the four categories if no treatment was available in the specific category of HRT. We defined discontinuation of overall HRT if no treatment was available in any of the four categories. Thus, each woman could contribute with HRT treatment or discontinuation periods several times. For analyses of the four HRT categories, we followed women as long as they did not change to a different category of HRT. We calculated exposure to and discontinuation of HRT for all prescriptions in the entire period from 1 January 1996 to 31 December 2008. This means that any discontinuation beginning in the first 30 days after discharge was registered and included in the analysis as a discontinuation if it continued beyond the first 30 days after discharge (which was the beginning of the follow-up time).

\section{Concomitant drugs and comorbidity}

We defined concomitant drugs as claimed prescriptions within 180 days before or 30 days after the myocardial infarction for $\beta$ blockers (ATC code C07), angiotensin converting enzyme inhibitors/angiotensin II receptor blockers (ATC code C09), statins (ATC code C10AA), and clopidogrel (ATC code B01AC04). We defined comorbidity with the modified Ontario acute myocardial infarction prediction rules by diagnosis from the index admission and one year before admission. ${ }^{30} 31$ The national registers have a low sensitivity for the diagnosis of heart failure, and they hold no information about left ventricle ejection fraction. ${ }^{32} \mathrm{We}$ therefore used prescriptions for loop diuretics (ATC code C03C) as a proxy for heart failure, as previously done. ${ }^{33}$ Similarly, we used prescriptions for glucose lowering drugs (ATC code A10) as a proxy for drug treated diabetes. We also obtained information about previous myocardial infarction, revascularisation (percutaneous coronary intervention (operation codes 30350, 30354, and KFNG) and coronary artery bypass graft surgery (operation codes 30009 to 30199 and KFNA to KFNE)).

\section{Outcomes}

We defined reinfarction as fatal or non-fatal myocardial infarction (ICD-10 codes I21 to I22) at least 30 days after discharge for the index myocardial infarction as done previously. ${ }^{34}$ We defined cardiovascular death as death due to a disease of the circulatory system (ICD10-code I00 to I99) and all cause death as death of any cause. Follow-up was from day 30 until 1 year after discharge.

\section{Statistical analysis}

We present baseline characteristics of the different groups of women as numbers with percentages or medians with interquartile ranges and compared them by using $\chi^{2}$ tests and analysis of variance. We categorised age into groups of 40-59 years, 60-69 years, 70-79 years, and 80 years and above (table $2 \Downarrow)$.

We calculated unadjusted incidence rates for reinfarction, cardiovascular mortality, and all cause mortality for discontinuation of and continued treatment with overall HRT and the four categories of HRT. We divided duration of discontinuation of HRT into 1-90 days, 91-180 days, 181-360 days, and 1-360 days. We did calculations and analyses for the periods 30-90 days, 91-180 days, 181-360 days, and 30-360 
days after discharge. We used a multivariable Cox proportional hazards model to calculate hazard ratios for reinfarction, cardiovascular mortality, and all cause mortality for various periods of discontinuation. We did this for both overall HRT and the four HRT categories, using continued treatment as the reference. The multivariable Cox model was adjusted for age group, year of myocardial infarction, comorbidity (previous myocardial infarction, revascularisation within 30 days of myocardial infarction, cerebrovascular disease, congestive heart failure, malignancy, cardiac dysrhythmias, chronic renal failure, acute renal failure, diabetes with complications, pulmonary oedema, shock), concomitant use of drugs ( $\beta$ blockers, angiotensin converting enzyme inhibitors, statins, loop diuretics, clopidogrel, glucose lowering drugs), and income group. We tested the model assumptions and found them to be valid. We did tests for interactions for the various periods of discontinuation of the HRT groups and age groups, year of myocardial infarction, revascularisation within 30 days after myocardial infarction, comorbidity, previous myocardial infarction, and concomitant drugs and for year of myocardial infarction and age groups. No interactions were evident, so we included no interactions in the final Cox model.

For all statistical analyses, we considered a level of 5\% to be statistically significant. We used SAS statistical software version 9.2 and Stata version 11 for all analyses. The study was conducted and reported in accordance with the Strengthening the Reporting of Observational Studies in Epidemiology (STROBE) recommendations. ${ }^{35}$

\section{Sensitivity analyses}

To make sure that the exclusion of women who died during the first 30 days after discharge did not seriously affect our results, we did sensitivity analyses of cardiovascular death and all cause death including these women and beginning follow-up at the day of discharge. We estimated the effect of an unmeasured confounder according to the "rule out" approach for the relevant reported results. ${ }^{36}$

\section{Results}

A total of 44099 women aged 40 or over on 1 January 1997 had a myocardial infarction in the period 1997 to 2008, but 10 494 of these women died during the first 30 days after discharge and were therefore excluded, as were the 71 women lost to follow-up (fig $1 \Downarrow$ ). Among the remaining 33534 women, 3322 (9.9\%) were using HRT at the time of myocardial infarction, and these women constituted the population of this study. The number of reinfarctions during follow-up was $282(8.5 \%), 357$ (10.7\%) women died of all causes, and 218 (6.6\%) died of cardiovascular causes.

Most women used the combination of systemic oestrogen and progestogen $(1100 ; 33.1 \%)$, followed by vaginal oestrogen ( 977 , $29.4 \%$ ) and systemic oestrogen alone $(954,28.7 \%)$. Only 291 (8.8\%) women used HRT belonging to the category "other HRT" (table $2 \Downarrow$ ). Baseline characteristics of women using different categories of HRT were very different, as is evident from table $2 \Downarrow$ and as we have previously found. ${ }^{25}$

Analyses of discontinuation in the first 30-360 days after myocardial infarction showed an association between discontinuation of vaginal oestrogen and a decreased risk of reinfarction (hazard ratio $0.54,95 \%$ confidence interval 0.34 to 0.86 ), as well as an insignificant association for discontinuation of systemic oestrogen $(0.56,0.28$ to 1.11$)$ and overall HRT $(0.90,0.68$ to 1.19$)$ (table $3 \Downarrow)$. We also found a statistically insignificant increase in cardiovascular mortality (hazard ratio
$1.39,0.73$ to 2.66 , for discontinuation of systemic oestrogen; $1.15,0.78$ to 1.72 , for vaginal oestrogen; and $1.21,0.90$ to 1.62 , for overall HRT) and all cause mortality (hazard ratio 1.17, 0.70 to 1.94 , for discontinuation of systemic oestrogen; $1.31,0.95$ to 1.83 , for vaginal oestrogen; and $1.22,0.97$ to 1.53 , for overall HRT).

When analysing the different durations of discontinuation, we found that discontinuation of overall HRT for 1-90 days was associated with an increased risk of cardiovascular mortality and all cause mortality but no increased risk of reinfarction (fig $2 \Downarrow)$. This increased risk was apparent for cardiovascular mortality only when discontinuation occurred in the period 30-90 days after discharge (hazard ratio $1.90,1.15$ to 3.12 ) and for all cause mortality in both the periods 30-90 days $(1.58,1.04$ to 2.39 ) and $91-180$ days after discharge (1.76, 1.08 to 2.87$)$. For 1-90 days of discontinuation of systemic oestrogen alone, we found increased cardiovascular mortality (hazard ratio 6.14, 1.95 to 19.3$)$ and all cause mortality $(3.23,1.30$ to 8.07$)$ during the first 30-90 days after discharge (fig $2 \Downarrow$ ). Again, we found a statistically insignificant lower risk of reinfarction. For 1-90 days of discontinuation of vaginal oestrogen, we found a decreased risk of reinfarction during the first 30-90 days after discharge (hazard ratio $0.36,0.16$ to 0.82 ) (fig $2 \Downarrow$ ). For all the above, the corresponding unadjusted incidence rates of continued and discontinued treatment were equivalent to the proportional hazard analyses (tables $3 \Downarrow, 4 \Downarrow, 5 \Downarrow$, and $6 \Downarrow$ ). For discontinuation of combinations of oestrogen and progestogen and for the category "other HRT," calculations were limited owing to very few endpoints (table $3 \Downarrow$, fig $2 \Downarrow$ ).

Tables $7 \Downarrow$ and $8 \Downarrow$ show the results of the sensitivity analyses. The associations between discontinuation and the endpoints did not change significantly after inclusion of the first 30 days in the analyses or after postponement of the time of discontinuation by seven or 14 days.

\section{Unmeasured confounding}

To test whether the low risk of reinfarction after discontinuation of vaginal oestrogen found in both the first year and the first 30-90 days after myocardial infarction could be due to unmeasured confounding, we tried to estimate the hypothetical size of such an unmeasured confounder, assuming a $20 \%$ prevalence of an unmeasured confounder in the population and a prevalence of discontinuation of $20 \% .^{36}$ The results indicate that an unmeasured confounder would be very unevenly distributed between the groups and have a very strong association with continued treatment (fig $3 \Downarrow$ and fig $4 \Downarrow$ ). A confounder or combination of confounders that could decrease the risk of reinfarction from 1.00 to 0.54 for discontinuation in the first year after myocardial infarction would have to increase the risk fivefold (fig $3 \Downarrow$ ) and thereby exceed the effects of any measured confounder in the study, such as diabetes or age 80 or over. However, to render the results statistically insignificant, a confounder would have to increase the risk only twofold. In the case of discontinuation of vaginal oestrogen in the first 30-90 days after myocardial infarction, a confounder would have to increase the risk less than twofold to make the result statistically insignificant (fig $4 \Downarrow$ ).

\section{Discussion}

This study is to our knowledge the first to look at whether women in a real life population who discontinue hormone replacement therapy after myocardial infarction have a lower risk of adverse cardiovascular events than do women who continue using HRT and whether discontinuation of different 
categories of HRT might carry different risks. Our main finding was that in women with myocardial infarction who followed treatment guidelines and discontinued HRT overall, we could not detect a decreased or increased risk of reinfarction, cardiovascular mortality, or all cause mortality during the first year after the index myocardial infarction. Discontinuation of vaginal oestrogen after myocardial infarction was associated with a decrease in risk of reinfarction in the first year and the first 30-90 days after discharge. Women in the vaginal oestrogen group had very different baseline characteristics and higher incidence rates compared with women in the other HRT categories, which is relevant in interpreting these results.

\section{Comparison with other studies}

Most trials of the cardiovascular efficacy and safety of HRT have used oral conjugated equine oestrogens with or without medroxyprogesterone acetate depending on whether the woman had an intact uterus, but the use of conjugated equine oestrogens in our population was very limited. ${ }^{4525}$ HRT covers a multitude of hormones, formulations, doses, and routes of administration and has favourable effects on endothelial function, serum lipids, lipoproteins, and markers of fibrinolysis, inflammation, and coagulation. ${ }^{97}$ These effects differ, however, between oral and transdermal oestrogen, probably because of the hepatic first pass effect with oral oestrogen. ${ }^{10-13}$ Vaginal oestrogen treatment was previously believed to have only local effects, but a recent study showed a fivefold increase in serum oestradiol after one week of vaginal treatment. ${ }^{14}$ Interestingly, a recent observational study in Denmark found no overall effect of oral HRT on risk of coronary artery disease, but both transdermal and vaginal HRT were associated with decreased risk. ${ }^{38}$ Our results, too, seem to imply that vaginal oestrogen has a systemic effect or, alternatively, that some unmeasured confounder is responsible for the observed difference. As this is an observational study, we can only speculate about, and not explain, what causes the observed lower risk of reinfarction in women who discontinue vaginal oestrogen.

We have previously found in a population of women using HRT at the time of myocardial infarction in the period 1997 to 2005 that more than $80 \%$ of women who survived one year after myocardial infarction claimed a new prescription for HRT in the first year after discharge. ${ }^{25}$ The vast majority of women continued use of the same category of HRT that they used at the time of myocardial infarction. This low rate of discontinuation might be because most women who discontinue HRT experience serious discomfort such as hot flushes and sleep disorders, which have a negative effect on their quality of life. Likewise, discontinuation of HRT can be especially difficult for women on long term HRT or for those who previously had severe climacteric symptoms. ${ }^{18-20} 39$ Discontinuation of long term HRT may lead to increases in plasminogen activator inhibitor 1 and to augmented endothelial dysfunction in women with coronary artery disease. Also, blood concentrations of low density lipoprotein cholesterol and total cholesterol increase in women who discontinue HRT. ${ }^{17}$ These findings suggest that discontinuation of HRT might cause a detrimental rebound effect that may contribute to adverse cardiovascular events. The period immediately after myocardial infarction is a pathophysiologically vulnerable time window, with endothelial dysfunction and elevated inflammatory markers. Hence, a possible rebound effect of discontinuation of HRT on these mechanisms might be especially detrimental during this period. ${ }^{22-24}$ That the post-infarction period may not be the optimal time to discontinue HRT would therefore seem plausible. The results reported here, in which discontinuation seems to have a greater effect in the first 30-90 days after myocardial infarction, suggest that this line of reasoning may be true.

Only a few studies have examined the effect of HRT on prognosis after myocardial infarction. An observational study of women admitted with myocardial infarction found that women using HRT at the time of admission had significantly lower in-hospital mortality than did women who did not use HRT and concluded that this could be explained by therapeutic effects of HRT, selection bias, or both. ${ }^{40}$ Among women who used HRT at the time of coronary artery stenting, repeat revascularisation has also been reported to be significantly reduced. ${ }^{41}$ Our study illustrates the importance of future randomised studies in this area concerning the use and discontinuation of HRT; however, adequately powered studies of this sort seem unlikely ever to be done.

\section{Strengths and limitations}

The main strength of this study is the complete and nationwide cohort of unselected women using HRT at the time of myocardial infarction, including information about concomitant drugs and comorbidity. The required registration by the Danish pharmacies and the reimbursement of medical expenses ensure that all social classes and women both in and out of the labour market were represented. Moreover, we were able to include women using all the formulations of HRT available on the market.

The study has several limitations inherent to its observational nature. We have no information on clinical parameters such as obesity and smoking status, and although the incorporation of, for example, concomitant drugs, comorbidity, and income in our analyses might capture some effects of the important cardiovascular risk factors that we lack information about in this study, we cannot rule out unmeasured confounding. The significantly lower risk of reinfarction seen after discontinuation of vaginal oestrogen might be due to unmeasured confounding even though such a confounder or combination of confounders would have to be highly prevalent and carry a great risk. The HRT doses and treatment durations were calculated approximations, and the true dates of beginning and discontinuing a treatment may differ from the calculated dates. The sensitivity analyses in which discontinuation was postponed for seven and 14 days did not alter the direction of the results, and discontinuation has previously been assessed using prescriptions and the same algorithm for calculating treatment intervals and discontinuation as in our study. ${ }^{42}$ However, we cannot rule out the possibility of unmeasured factors influencing our calculations, as the accuracy of assessment of discontinuation by monitoring of prescriptions is unknown. We lack information about the precise indications for use or discontinuation of HRT and about symptoms that may be a confounder, as hot flushes may be a marker of increased cardiovascular risk. ${ }^{43}$ Furthermore, the well known observation that discontinuation of drugs as well as of placebo is associated with increased mortality must clearly be considered for a balanced interpretation of our results. ${ }^{44} 45$

\section{Conclusion}

The main result of this study is that we found no certain increased or a decreased risk of reinfarction or death with continuing HRT after a myocardial infarction. The 95\% confidence limits rule out neither a modest benefit nor a worrisome increase in risk. These figures are valuable when a possible cardiovascular risk needs to be balanced with menopausal symptoms for the individual patient. 


\section{What is already known on this topic}

Guidelines recommend discontinuation of HRT after myocardial infarction, even though randomised trials have not found an increase in cardiovascular risk in women with coronary heart disease

However, around $80 \%$ of women do not follow these guidelines

\section{What this study adds}

No certain increased or decreased risk of reinfarction or death with continuing HRT after a myocardial infarction was found These figures are valuable when a possible cardiovascular risk needs to be balanced with menopausal symptoms for the individual patient

Contributors: D-MB, PRH, SZA, CT-P, and GHG were involved in the study conception and design. D-MB and PRH obtained funding. D-MB, $\mathrm{JL}, \mathrm{CT}-\mathrm{P}$, and GHG were involved in acquisition of data. D-MB, PRH, $\mathrm{RS}, \mathrm{JL}, \mathrm{OA}, \mathrm{CA}, \mathrm{CT}-\mathrm{P}$, and GHG were responsible for analysis and interpretation of data. DMB, JL, OA, CT-P, and GHG did the statistical analysis. D-MB drafted the manuscript, and all authors critically revised it for important intellectual content. D-MB, CT-P provided administrative, technical, or material support. PRH, SZA, CT-P, and GHG supervised the study. D-MB and GHG are the guarantors.

Funding: D-MB was supported by the Danish Heart Foundation (grant 08-4-R65-A1904-B844-22440F) and the Lundbeck Foundation (grant R31-A2566). None of the funding sponsors were involved in the design and conduct of the study; in collection, management, analysis, and interpretation of the data; or in preparation, review, and approval of the manuscript.

Competing interests: All authors have completed the ICMJE uniform disclosure form at www.icmje.org/coi_disclosure.pdf (available on request from the corresponding author) and declare: CT-P has received consultant fees from Sanofi, Neurosearch, Cardiome, and Merck. All other authors declare no support from any organisations for the submitted work; no financial relationships with any organisations that might have an interest in the submitted work in the previous three years; no other relationships or activities that could appear to have influenced the submitted work.

Ethical approval: The Danish Data Protection Agency approved the study (No 2007-41-1667). Retrospective register studies do not require ethical approval in Denmark.

Data sharing: No additional data available.

American College of Physicians. Guidelines for counseling postmenopausal women about preventive hormone therapy. Ann Intern Med 1992;117:1038-41.

2 Barrett-Connor E, Grady D. Hormone replacement therapy, heart disease, and other considerations. Annu Rev Public Health 1998;19:55-72.

3 Stampfer MJ, Colditz GA. Estrogen replacement therapy and coronary heart disease: a quantitative assessment of the epidemiologic evidence. Prev Med 1991;20:47-63.

4 Hulley S, Grady D, Bush T, Furberg C, Herrington D, Riggs B, et al. Randomized trial of estrogen plus progestin for secondary prevention of coronary heart disease in postmenopausal women. JAMA 1998;280:605-13.

5 Rossouw JE, Anderson GL, Prentice RL, LaCroix AZ, Kooperberg C, Stefanick ML, et al Risks and benefits of estrogen plus progestin in healthy postmenopausal women: principal results from the Women's Health Initiative randomized controlled trial. JAMA 2002;288:321-33.

6 Mosca L, Banka CL, Benjamin EJ, Berra K, Bushnell C, Dolor RJ, et al. Evidence-based guidelines for cardiovascular disease prevention in women: 2007 update. Circulation 2007;115:1481-501.

7 Mosca L, Appel LJ, Benjamin EJ, Berra K, Chandra-Strobos N, Fabunmi RP, et al. Evidence-based guidelines for cardiovascular disease prevention in women. Circulation 2004:109:672-93.

8 Naftolin F, Schneider HP, Sturdee DW, Birkhauser M, Brincat MP, Gambacciani M, et al. Guidelines for hormone treatment of women in the menopausal transition and beyond. Climacteric 2004;7:333-7.

9 Mendelsohn ME, Karas RH. The protective effects of estrogen on the cardiovascular system. N Engl J Med 1999;340:1801-11.

10 Vehkavaara S, Hakala-Ala-Pietila T, Virkamaki A, Bergholm R, Ehnholm C, Hovatta O, et al. Differential effects of oral and transdermal estrogen replacement therapy on endothelial function in postmenopausal women. Circulation 2000;102:2687-93.

11 Vongpatanasin W, Tuncel M, Wang Z, Arbique D, Mehrad B, Jialal I. Differential effects of oral versus transdermal estrogen replacement therapy on C-reactive protein in postmenopausal women. J Am Coll Cardiol 2003;41:1358-63.

12 Vehkavaara S, Silveira A, Hakala-Ala-Pietila T, Virkamaki A, Hovatta O, Hamsten A, et al. Effects of oral and transdermal estrogen replacement therapy on markers of coagulation, fibrinolysis, inflammation and serum lipids and lipoproteins in postmenopausal women. Thromb Haemost 2001;85:619-25.
13 Vrablik M, Fait T, Kovar J, Poledne R, Ceska R. Oral but not transdermal estrogen replacement therapy changes the composition of plasma lipoproteins. Metabolism 2008;57:1088-92.

14 Labrie F, Cusan L, Gomez JL, Cote I, Berube R, Belanger P, et al. Effect of one-week treatment with vaginal estrogen preparations on serum estrogen levels in postmenopausal women. Menopause 2009:16:30-6.

15 Greiner DZ, Personius BE, Andrews TC. Effects of withdrawal of chronic estrogen therapy on brachial artery vasoreactivity in women with coronary artery disease. Am J Cardiol 1999;83:247-9, A5.

16 Kalela A, Jokela H, Lehtimaki T, Uppa H, Kunnas T, Teisala K, et al. Effect of the cessation of long-term hormone replacement therapy on plasma plasminogen activator inhibitor-1 and fibrinogen. Eur J Obstet Gynecol Reprod Biol 2006;125:217-20.

17 Pettee KK, Kriska AM, Conroy MB, Johnson BD, Orchard TJ, Goodpaster BH, et al. Discontinuing hormone replacement therapy: attenuating the effect on CVD risk with lifestyle changes. Am J Prev Med 2007;32:483-9.

18 Grady D, Sawaya GF. Discontinuation of postmenopausal hormone therapy. Am J Med 2005;118(suppl 12B):163-5.

19 Haimov-Kochman R, Barak-Glantz E, Ein-Mor E, Arbel R, Brzezinski A, Milwidsky A, et al. Duration not severity of the climacteric syndrome predicts resumption of hormone therapy after discontinuation: a prospective cohort study. Hum Reprod 2006;21:2450-4.

20 Horner E, Fleming J, Studd J. A study of women on long-term hormone replacement therapy and their attitude to suggested cessation. Climacteric 2006;9:459-63.

21 Anderson JL, Adams CD, Antman EM, Bridges CR, Califf RM, Casey DE Jr, et al. ACC/AHA 2007 guidelines for the management of patients with unstable angina/non ST-elevation myocardial infarction: a report of the American College of Cardiology/American Heart Association Task Force on Practice Guidelines (Writing Committee to Revise the 2002 Guidelines for the Management of Patients with Unstable Angina/Non ST-Elevation Myocardial Infarction): developed in collaboration with the American College of Emergency Physicians, the Society for Cardiovascular Angiography and Interventions, and the Society of Thoracic Surgeons: endorsed by the American Association of Cardiovascular and Pulmonary Rehabilitation and the Society for Academic Emergency Medicine. Circulation 2007;116:e148-304.

22 Fichtlscherer S, Breuer S, Zeiher AM. Prognostic value of systemic endothelial dysfunction in patients with acute coronary syndromes: further evidence for the existence of the "vulnerable" patient. Circulation 2004;110:1926-32.

23 Buffon A, Biasucci LM, Liuzzo G, D'Onofrio G, Crea F, Maseri A. Widespread coronary inflammation in unstable angina. N Engl J Med 2002;347:5-12.

24 Biasucci LM, Liuzzo G, Grillo RL, Caligiuri G, Rebuzzi AG, Buffon A, et al. Elevated levels of $C$-reactive protein at discharge in patients with unstable angina predict recurrent instability. Circulation 1999;99:855-60.

25 Bretler DM, Hansen PR, Abildstrom SZ, Jorgensen CH, Sorensen R, Hansen ML, et al. Use and discontinuation of hormone replacement therapy in women with myocardial infarction: a nationwide study. Br J Clin Pharmacol 2011:71:105-15.

26 Nordic Medico-Statistical Committee (NOMESCO). NOMESCO Classification of Surgical Procedures (NCSP), version 1.15. NOMESCO, 2010 (available at http://nomesco-da.nomnos.dk/filer/publikationer/NCSP\%201_15.pdf)

27 Gaist D, Sorensen HT, Hallas J. The Danish prescription registries. Dan Med Bull 1997:44:445-8

28 Madsen M, Davidsen M, Rasmussen S, Abildstrom SZ, Osler M. The validity of the diagnosis of acute myocardial infarction in routine statistics: a comparison of mortality and hospital discharge data with the Danish MONICA registry. J Clin Epidemiol 2003;56:124-30

29 Olesen JB, Hansen PR, Abildstrom SZ, Andersson C, Weeke P, Schmiegelow M, et al. Valproate attenuates the risk of myocardial infarction in patients with epilepsy: a nationwide cohort study. Pharmacoepidemiol Drug Saf 2011:20:146-53.

30 Tu JV, Austin PC, Walld R, Roos L, Agras J, McDonald KM. Development and validation of the Ontario acute myocardial infarction mortality prediction rules. J Am Coll Cardiol 2001;37:992-7.

31 Vermeulen MJ, Tu JV, Schull MJ. ICD-10 adaptations of the Ontario acute myocardial infarction mortality prediction rules performed as well as the original versions. J Clin Epidemiol 2007:60:971-4

32 Kumler T, Gislason GH, Kirk V, Bay M, Nielsen OW, Kober L, et al. Accuracy of a heart failure diagnosis in administrative registers. Eur J Heart Fail 2008;10:658-60.

33 Gislason GH, Rasmussen JN, Abildstrom SZ, Gadsboll N, Buch P, Friberg J, et al. Long-term compliance with beta-blockers, angiotensin-converting enzyme inhibitors, and statins after acute myocardial infarction. Eur Heart J 2006;27:1153-8.

34 Buch P, Rasmussen S, Gislason GH, Rasmussen JN, Kober L, Gadsboll N, et al. Tempora decline in the prognostic impact of a recurrent acute myocardial infarction 1985 to 2002. Heart 2007;93:210-5.

35 Von Elm E, Altman DG, Egger M, Pocock SJ, Gotzsche PC, Vandenbroucke JP. The strengthening the reporting of observational studies in epidemiology (STROBE) statement: guidelines for reporting observational studies. Lancet 2007;370:1453-7.

36 Schneeweiss $\mathrm{S}$. Sensitivity analysis and external adjustment for unmeasured confounders in epidemiologic database studies of therapeutics. Pharmacoepidemiol Drug Saf 2006;15:291-303

37 Yeboah J, Klein K, Brosnihan B, Reboussin D, Herrington DM. Effects of hormone therapy on soluble cell adhesion molecules in postmenopausal women with coronary artery disease. Menopause 2008:15:1060-4. 
38 Lokkegaard E, Andreasen AH, Jacobsen RK, Nielsen LH, Agger C, Lidegaard O. Hormone therapy and risk of myocardial infarction: a national register study. Eur Heart $J$ 2008:29:2660-8.

39 Welton AJ, Vickers MR, Kim J, Ford D, Lawton BA, MacLennan AH, et al. Health related quality of life after combined hormone replacement therapy: randomised controlled trial. BMJ 2008;337:a1190.

40 Shlipak MG, Angeja BG, Go AS, Frederick PD, Canto JG, Grady D. Hormone therapy and in-hospital survival after myocardial infarction in postmenopausal women. Circulation 2001;104:2300-4.

41 Khan MA, Liu MW, Singh D, Pal A, Chio FL, Lawson D, et al. Long-term (three years) effect of estrogen replacement therapy on major adverse cardiac events in postmenopausal women after intracoronary stenting. Am J Cardiol 2000;86:330-3.

42 Raunso J, Selmer C, Olesen JB, Charlot MG, Olsen AM, Bretler DM, et al. Increased short-term risk of thrombo-embolism or death after interruption of warfarin treatment in patients with atrial fibrillation. Eur Heart $J$ 2011; published online 23 December.

43 Gorodeski EZ. Are hot flashes linked to cardiovascular risk? It is too early to tell. Menopause 2010;17:443-4.
44 Collet JP, Montalescot G, Steg PG, Steinhubl SR, Fox KA, Hu TF, et al. Clinical outcomes according to permanent discontinuation of clopidogrel or placebo in the CHARISMA trial. Arch Cardiovasc Dis 2009;102:485-96.

45 Simpson SH, Eurich DT, Majumdar SR, Padwal RS, Tsuyuki RT, Varney J, et al. A meta-analysis of the association between adherence to drug therapy and mortality. BMJ 2006;333:15.

\section{Accepted: 22 February 2012}

\section{Cite this as: BMJ 2012;344:e1802}

This is an open-access article distributed under the terms of the Creative Commons Attribution Non-commercial License, which permits use, distribution, and reproduction in any medium, provided the original work is properly cited, the use is non commercial and is otherwise in compliance with the license. See: http://creativecommons.org/licenses/by$\mathrm{nc} / 2.0 /$ and http://creativecommons.org/licenses/by-nc/2.0/legalcode. 


\section{Tables}

\section{Table 1| Categories of hormone replacement therapy (HRT)}

\section{HRT category}

1. Systemic oestrogen (oral, intramuscular, nasal, or transdermal administration)

2. Systemic oestrogen and progestogen, continuous or cyclic* (oestrogen: oral, intramuscular, nasal, or transdermal administration; progestogen: intrauterine, transdermal, or oral administration)

3. Vaginal oestrogen

4. Other HRT
Anatomical therapeutic chemical system codes

G03C A03, G03C A04, G03C A53, G03C A57

Continuous: G03F A01, G03F A11, G03F A12, G03F A15, G0F A17; cyclic: G03F B01, G03F B05, G03F B06, G03F B09, G03F B11, G03H B01. Or oestrogen from category 1 + progestogen from category 4

Vaginal tablet: G03C A03, G03C A04, G03C A57, G03C B01; vaginal ring: G03C A03; vaginal cream: G03C A04

Progestogen intrauterine device: G02B A03; raloxifene: G03X C01; tibolone: G03D C05, G03C X01; progestogen alone: G03D A02, G03D A04, G03D B01, G03D C02, G03D C03. Or any combination of categories 1 and 3 or 2 and 3

${ }^{*}$ Continuous combined oestrogen/progestogen: daily doses of both oestrogen and progestogen; cyclic combined oestrogen/progestogen: daily doses of oestrogen and intermittent periods with daily doses of progestogen. 


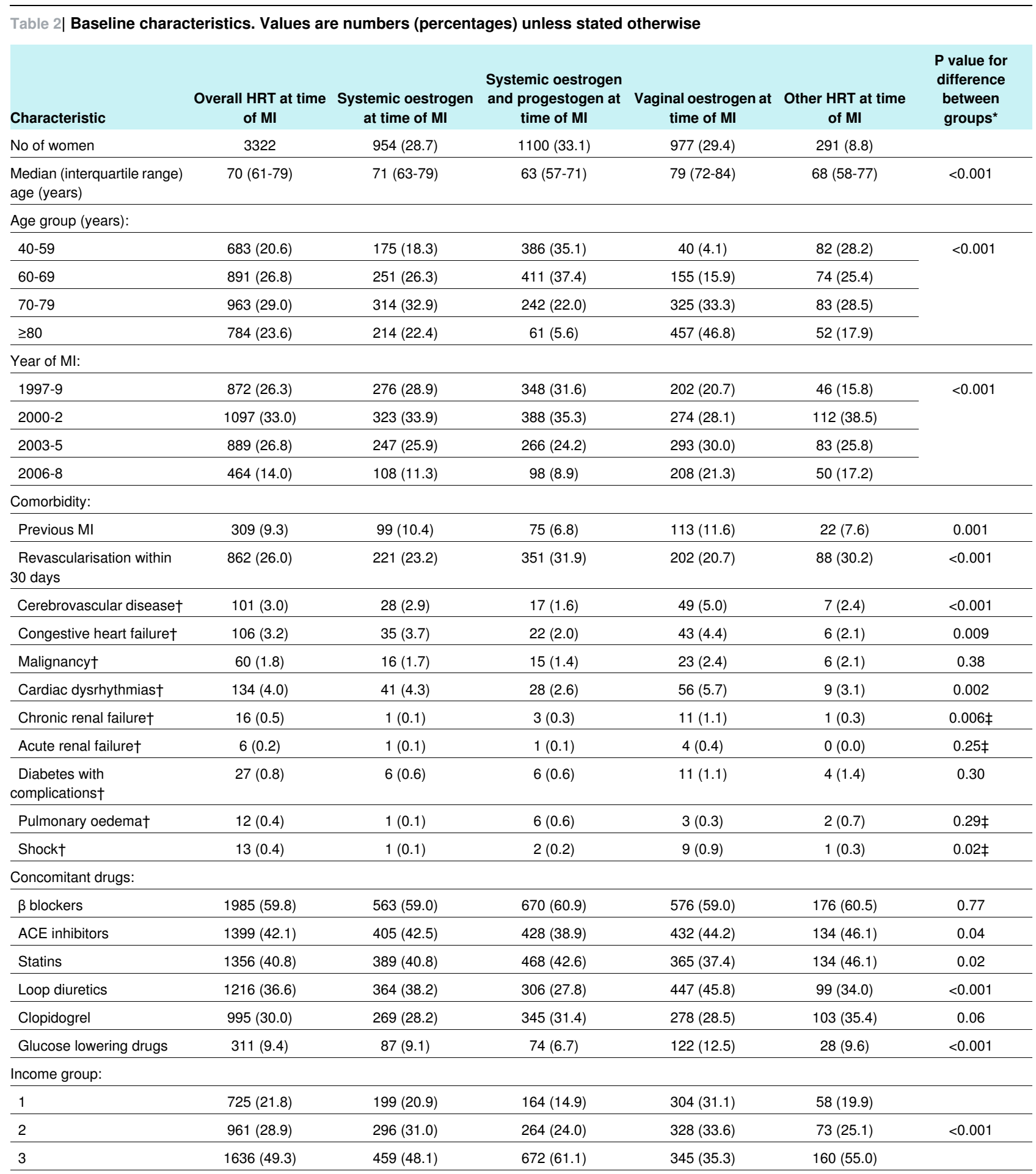

$\mathrm{ACE}=$ angiotensin converting enzyme; HRT=hormone replacement therapy; $\mathrm{Ml}=$ myocardial infarction.

${ }^{*} \chi^{2}$ test for categorical variables and analysis of variance for continuous variables.

†According to modified Ontario acute myocardial infarction prediction rules.

$\ddagger \chi^{2}$ test may not be valid owing to very few observations. 


\begin{tabular}{|c|c|c|c|c|c|c|}
\hline 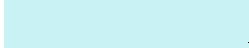 & \multicolumn{2}{|c|}{ Reinfarction } & \multicolumn{2}{|c|}{ Cardiovascular death } & \multicolumn{2}{|c|}{ All cause death } \\
\hline & Discontinuation & $\begin{array}{l}\text { Continued } \\
\text { treatment }\end{array}$ & Discontinuation & $\begin{array}{l}\text { Continued } \\
\text { treatment }\end{array}$ & Discontinuation & $\begin{array}{l}\text { Continued } \\
\text { treatment }\end{array}$ \\
\hline \multicolumn{7}{|c|}{ Hormone replacement therapy overall } \\
\hline Hazard ratio* $(95 \% \mathrm{Cl})$ & 0.90 (0.68 to 1.19$)$ & Reference & $1.21(0.90$ to 1.62$)$ & Reference & $1.22(0.97$ to 1.53$)$ & Reference \\
\hline Incidence rate $†$ & 90.9 & 112.9 & 91.9 & 74.2 & 156.3 & 119.2 \\
\hline No of events & 66 & 216 & 70 & 148 & 119 & 238 \\
\hline Person years & 725.7 & 1912.5 & 761.6 & 1995.8 & 761.6 & 1995.8 \\
\hline \multicolumn{7}{|l|}{ Systemic oestrogen } \\
\hline Hazard ratio* $(95 \% \mathrm{Cl})$ & $0.56(0.28$ to 1.11$)$ & Reference & 1.39 (0.73 to 2.66$)$ & Reference & 1.17 (0.70 to 1.94$)$ & Reference \\
\hline Incidence rate† & 58.7 & 116.1 & 80.3 & 60.6 & 126.2 & 111.1 \\
\hline No of events & 10 & 66 & 14 & 36 & 22 & 66 \\
\hline Person years & 170.5 & 568.5 & 174.3 & 594.0 & 174.3 & 594.0 \\
\hline \multicolumn{7}{|c|}{ Systemic oestrogen and progestogen } \\
\hline Hazard ratio* $(95 \% \mathrm{Cl})$ & $0.30(0.09$ to 0.96$)$ & Reference & 0.94 (0.37 to 2.39$)$ & Reference & $0.96(0.53$ to 1.75$)$ & Reference \\
\hline Incidence rate† & 16.9 & 85.9 & 43.4 & 33.4 & 89.0 & 83.7 \\
\hline No of events & 3 & 59 & 6 & 31 & 16 & 60 \\
\hline Person years & 177.9 & 686.8 & 179.8 & 716.8 & 179.8 & 716.8 \\
\hline \multicolumn{7}{|l|}{ Vaginal oestrogen } \\
\hline Hazard ratio* $(95 \% \mathrm{Cl})$ & $0.54(0.34$ to 0.86$)$ & Reference & 1.15 (0.78 to 1.72$)$ & Reference & 1.31 (0.95 to 1.83 ) & Reference \\
\hline Incidence rate† & 78.1 & 168.4 & 139.7 & 136.8 & 212.5 & 189.4 \\
\hline No of events & 26 & 68 & 47 & 59 & 73 & 80 \\
\hline Person years & 332.8 & 403.8 & 343.5 & 422.3 & 343.5 & 422.3 \\
\hline \multicolumn{7}{|c|}{ Other hormone replacement therapy } \\
\hline Hazard ratio* $(95 \% \mathrm{Cl})$ & $0.11(0.01$ to 2.20$)$ & Reference & 0.60 (0.03 to 11.8$)$ & Reference & 1.00 (0.24 to 4.28$)$ & Reference \\
\hline Incidence rate† & 26.3 & 105.7 & 63.9 & 25.5 & 101.2 & 115.0 \\
\hline No of events & 1 & 16 & 1 & 10 & 4 & 18 \\
\hline Person years & 38.0 & 151.3 & 39.2 & 156.5 & 39.2 & 156.5 \\
\hline
\end{tabular}


Table 4| Unadjusted incidence rates of reinfarction, cardiovascular mortality, and all cause mortality for discontinuation of HRT overall

\begin{tabular}{|c|c|c|c|c|c|c|c|c|c|c|c|c|}
\hline & \multicolumn{4}{|c|}{ Reinfarction } & \multicolumn{4}{|c|}{ Cardiovascular mortality } & \multicolumn{4}{|c|}{ All cause mortality } \\
\hline & \multirow[b]{2}{*}{$\begin{array}{c}\text { Continued } \\
\text { HRT }\end{array}$} & \multicolumn{3}{|c|}{ HRT discontinued } & \multirow[b]{2}{*}{$\begin{array}{c}\text { Continued } \\
\text { HRT }\end{array}$} & \multicolumn{3}{|c|}{ HRT discontinued } & \multirow[b]{2}{*}{$\begin{array}{c}\text { Continued } \\
\text { HRT }\end{array}$} & \multicolumn{3}{|c|}{ HRT discontinued } \\
\hline & & 1-90 days & $\begin{array}{c}91-180 \\
\text { days }\end{array}$ & $\begin{array}{c}181-360 \\
\text { days }\end{array}$ & & 1-90 days & $\begin{array}{c}91-180 \\
\text { days }\end{array}$ & $\begin{array}{c}181-360 \\
\text { days }\end{array}$ & & $1-90$ days & $\begin{array}{c}\text { 91-180 } \\
\text { days }\end{array}$ & $\begin{array}{c}181-360 \\
\text { days }\end{array}$ \\
\hline \multicolumn{13}{|c|}{ 30-90 days after myocardial infarction } \\
\hline $\begin{array}{l}\text { Incidence } \\
\text { rate* }^{*}\end{array}$ & 237.7 & 198.5 & - & - & 116.7 & 257.3 & - & - & 180.8 & 349.9 & - & - \\
\hline Failures & 102 & 19 & - & - & 51 & 25 & - & - & 79 & 34 & - & - \\
\hline $\begin{array}{l}\text { Person } \\
\text { years }\end{array}$ & 429.2 & 95.7 & - & - & 436.9 & 97.2 & - & - & 436.9 & 97.2 & - & - \\
\hline \multicolumn{13}{|c|}{ 91-180 days after myocardial infarction } \\
\hline $\begin{array}{l}\text { Incidence } \\
\text { rate }^{*}\end{array}$ & 108.9 & 157.1 & 63.4 & - & 80.3 & 105.4 & 97.7 & - & 104.7 & 210.8 & 171.0 & - \\
\hline Failures & 60 & 17 & 5 & - & 46 & 12 & 8 & - & 60 & 24 & 14 & - \\
\hline $\begin{array}{l}\text { Person } \\
\text { years }\end{array}$ & 551.2 & 108.2 & 78.9 & - & 573.0 & 113.9 & 81.9 & - & 573.0 & 113.9 & 81.9 & - \\
\hline \multicolumn{13}{|c|}{ 181-360 days after myocardial infarction } \\
\hline $\begin{array}{l}\text { Incidence } \\
\text { rate }^{*}\end{array}$ & 57.9 & 69.4 & 80.4 & 31.8 & 51.7 & 51.0 & 60.5 & 50.2 & 100.4 & 87.4 & 105.8 & 105.5 \\
\hline Failures & 54 & 9 & 10 & 6 & 51 & 7 & 8 & 10 & 99 & 12 & 14 & 21 \\
\hline $\begin{array}{l}\text { Person } \\
\text { years }\end{array}$ & 932.1 & 129.7 & 124.4 & 188.8 & 986.0 & 137.3 & 132.3 & 199.1 & 986.0 & 137.3 & 132.3 & 199.1 \\
\hline
\end{tabular}

HRT=hormone replacement therapy.

*Unadjusted incidence rates per 1000 person years. 
Table 5| Unadjusted incidence rates of reinfarction, cardiovascular mortality and all cause mortality for discontinuation of systemic oestrogen

\begin{tabular}{|c|c|c|c|c|c|c|c|c|c|c|c|c|}
\hline & \multicolumn{4}{|c|}{ Reinfarction } & \multicolumn{4}{|c|}{ Cardiovascular mortality } & \multicolumn{4}{|c|}{ All cause mortality } \\
\hline & \multirow[b]{2}{*}{$\begin{array}{c}\text { Continued } \\
\text { HRT }\end{array}$} & \multicolumn{3}{|c|}{ HRT discontinued } & \multirow[b]{2}{*}{$\begin{array}{c}\text { Continued } \\
\text { HRT }\end{array}$} & \multicolumn{3}{|c|}{ HRT discontinued } & \multirow[b]{2}{*}{$\begin{array}{c}\text { Continued } \\
\text { HRT }\end{array}$} & \multicolumn{3}{|c|}{ HRT discontinued } \\
\hline & & $\begin{array}{l}1-90 \\
\text { days }\end{array}$ & $\begin{array}{c}91-180 \\
\text { days }\end{array}$ & $\begin{array}{c}\text { 181-360 } \\
\text { days }\end{array}$ & & 1-90 days & $\begin{array}{c}\text { 91-180 } \\
\text { days }\end{array}$ & $\begin{array}{c}\text { 181-360 } \\
\text { days }\end{array}$ & & 1-90 days & $\begin{array}{c}\text { 91-180 } \\
\text { days }\end{array}$ & $\begin{array}{c}181-360 \\
\text { days }\end{array}$ \\
\hline \multicolumn{13}{|c|}{ 30-90 days after myocardial infarction } \\
\hline $\begin{array}{l}\text { Incidence } \\
\text { rate* }^{*}\end{array}$ & 184.5 & 109.7 & - & - & 75.5 & 327.4 & - & - & 151.1 & 382.0 & - & - \\
\hline Failures & 24 & 2 & - & - & 10 & 6 & - & - & 20 & 7 & - & - \\
\hline $\begin{array}{l}\text { Person } \\
\text { years }\end{array}$ & 130.1 & 18.2 & - & - & 132.3 & 18.3 & - & - & 132.3 & 18.3 & - & - \\
\hline \multicolumn{13}{|c|}{ 91-180 days after myocardial infarction } \\
\hline $\begin{array}{l}\text { Incidence } \\
\text { rate }^{*}\end{array}$ & 116.0 & 36.0 & NA & - & 88.3 & 69.5 & 59.9 & - & 117.8 & 173.7 & 59.9 & - \\
\hline Failures & 19 & 1 & 0 & - & 15 & 2 & 1 & - & 20 & 5 & 1 & - \\
\hline $\begin{array}{l}\text { Person } \\
\text { years } \\
\end{array}$ & 163.8 & 27.8 & 16.6 & - & 169.8 & 28.8 & 16.7 & - & 169.8 & 28.8 & 16.7 & - \\
\hline \multicolumn{13}{|c|}{$181-360$ days after myocardial infarction } \\
\hline $\begin{array}{l}\text { Incidence } \\
\text { rate* }^{*}\end{array}$ & 83.8 & 65.8 & 125.0 & 22.0 & 37.7 & 31.5 & 60.5 & 43.7 & 89.1 & 63.0 & 90.8 & 87.5 \\
\hline Failures & 23 & 2 & 4 & 1 & 11 & 1 & 2 & 2 & 26 & 2 & 3 & 4 \\
\hline $\begin{array}{l}\text { Person } \\
\text { years }\end{array}$ & 274.5 & 30.4 & 32.0 & 45.4 & 291.9 & 31.8 & 33.0 & 45.7 & 291.9 & 31.8 & 33.0 & 45.7 \\
\hline
\end{tabular}

HRT=hormone replacement therapy.

*Unadjusted incidence rates per 1000 person years. 


\begin{tabular}{|c|c|c|c|c|c|c|c|c|c|c|c|c|}
\hline & \multicolumn{4}{|c|}{ Reinfarction } & \multicolumn{4}{|c|}{ Cardiovascular mortality } & \multicolumn{4}{|c|}{ All cause mortality } \\
\hline & \multirow[b]{2}{*}{$\begin{array}{l}\text { Continued } \\
\text { HRT }\end{array}$} & \multicolumn{3}{|c|}{ HRT discontinued } & \multirow[b]{2}{*}{$\begin{array}{c}\text { Continued } \\
\text { HRT }\end{array}$} & \multicolumn{3}{|c|}{ HRT discontinued } & \multirow[b]{2}{*}{$\begin{array}{c}\text { Continued } \\
\text { HRT }\end{array}$} & \multicolumn{3}{|c|}{ HRT discontinued } \\
\hline & & $\begin{array}{l}1-90 \\
\text { days }\end{array}$ & $\begin{array}{c}91-180 \\
\text { days }\end{array}$ & $\begin{array}{c}181-360 \\
\text { days }\end{array}$ & & $1-90$ days & $\begin{array}{c}91-180 \\
\text { days }\end{array}$ & $\begin{array}{c}181-360 \\
\text { days }\end{array}$ & & $1-90$ days & $\begin{array}{c}91-180 \\
\text { days }\end{array}$ & $\begin{array}{c}181-360 \\
\text { days }\end{array}$ \\
\hline \multicolumn{13}{|c|}{ 30-90 days after myocardial infarction } \\
\hline $\begin{array}{l}\text { Incidence } \\
\text { rate }^{*}\end{array}$ & 343.0 & 124.2 & - & - & 213.5 & 282.9 & - & - & 284.7 & 371.2 & - & - \\
\hline Failures & 33 & 7 & - & - & 21 & 16 & - & - & 28 & 21 & - & - \\
\hline $\begin{array}{l}\text { Person } \\
\text { years }\end{array}$ & 96.2 & 56.4 & - & - & 98.4 & 56.6 & - & - & 98.4 & 56.6 & - & - \\
\hline \multicolumn{13}{|c|}{91 to 180 days after myocardial infarction } \\
\hline $\begin{array}{l}\text { Incidence } \\
\text { rate }^{*}\end{array}$ & 184.9 & 90.9 & 107.7 & - & 160.7 & 173.4 & 128.9 & - & 200.9 & 260.1 & 236.3 & - \\
\hline Failures & 22 & 4 & 5 & - & 20 & 8 & 6 & - & 25 & 12 & 11 & - \\
\hline $\begin{array}{l}\text { Person } \\
\text { years }\end{array}$ & 119.0 & 44.0 & 46.4 & - & 124.4 & 46.1 & 46.5 & - & 124.4 & 46.1 & 46.5 & - \\
\hline \multicolumn{13}{|c|}{181 to 360 days after myocardial infarction } \\
\hline $\begin{array}{l}\text { Incidence } \\
\text { rate* }\end{array}$ & 68.9 & 42.7 & 88.9 & 42.4 & 90.2 & 79.3 & 104.1 & 83.5 & 135.3 & 119.0 & 187.4 & 146.2 \\
\hline Failures & 13 & 2 & 4 & 4 & 18 & 4 & 5 & 8 & 27 & 6 & 9 & 14 \\
\hline $\begin{array}{l}\text { Person } \\
\text { years }\end{array}$ & 188.6 & 46.8 & 45.0 & 94.3 & 199.5 & 50.4 & 48.0 & 95.8 & 199.5 & 50.4 & 48.0 & 95.8 \\
\hline
\end{tabular}

Table 6 Unadjusted incidence rates of reinfarction, cardiovascular mortality, and all cause mortality for discontinuation of vaginal oestrogen $\mathrm{HRT}=$ hormone replacement therapy.

*Unadjusted incidence rates per 1000 person years. 
Table 7| Sensitivity analysis: hazard ratios $(95 \% \mathrm{Cl})$ for discontinuation ${ }^{\star}$ after inclusion in analyses of women who died in first 30 days after myocardial infarction

Death HRT overall Systemic oestrogen Systemic oestrogen and progestogen Vaginal oestrogen

\begin{tabular}{lllll} 
Cardiovascular death $1.24(0.96$ to 1.62$)$ & $1.47(0.86$ to 2.52$)$ & $1.01(0.48$ to 2.14$)$ & $1.17(0.83$ to 1.65$)$ \\
\hline All cause death & $1.26(1.02$ to 1.54$)$ & $1.30(0.85$ to 2.00$)$ & $1.02(0.61$ to 1.70$)$ & $1.30(0.98$ to 1.73$)$
\end{tabular}

$\begin{array}{lllll}\text { All cause death } & 1.26(1.02 \text { to } 1.54) & 1.30(0.85 \text { to } 2.00) & 1.02(0.61 \text { to } 1.70) & 1.30(0.98 \text { to } 1.73)\end{array}$

$\mathrm{HRT}=$ hormone replacement therapy

*Discontinuation 1-360 days after MI myocardial infarction. 
Table 8| Sensitivity analysis: hazard ratios $(95 \% \mathrm{Cl})$ for discontinuation* after postponement of discontinuation date by 7 and 14 days

\begin{tabular}{llll}
$\begin{array}{l}\text { Postponement } \\
\text { HRT overall: }\end{array}$ & Reinfarction & Cardiovascular death & All cause death \\
\hline 7 days & $0.91(0.69$ to 1.22$)$ & $1.09(0.80$ to 1.48$)$ & $1.14(0.90$ to 1.44$)$ \\
\hline 14 days & $0.86(0.63$ to 1.15$)$ & $1.02(0.74$ to 1.39$)$ & $1.12(0.89$ to 1.43$)$ \\
\hline Systemic oestrogen: & & & \\
\hline 7 days & $0.54(0.26$ to 1.11$)$ & $1.34(0.69$ to 2.61$)$ & $1.17(0.70$ to 1.97$)$ \\
\hline 14 days & $0.51(0.24$ to 1.09$)$ & $1.30(0.66$ to 2.69$)$ & $1.18(0.70$ to 2.00$)$ \\
\hline Vaginal oestrogen: & & & \\
\hline 7 days & $0.50(0.31$ to 0.80$)$ & $0.94(0.62$ to 1.41$)$ & $1.14(0.82$ to 1.60$)$ \\
\hline 14 days & $0.48(0.30$ to 0.79$)$ & $0.86(0.56$ to 1.30$)$ & $1.11(0.79$ to 1.53$)$ \\
\hline
\end{tabular}

HRT=hormone replacement therapy.

*Discontinuation in 1-360 days after Ml myocardial infarction. 


\section{Figures}

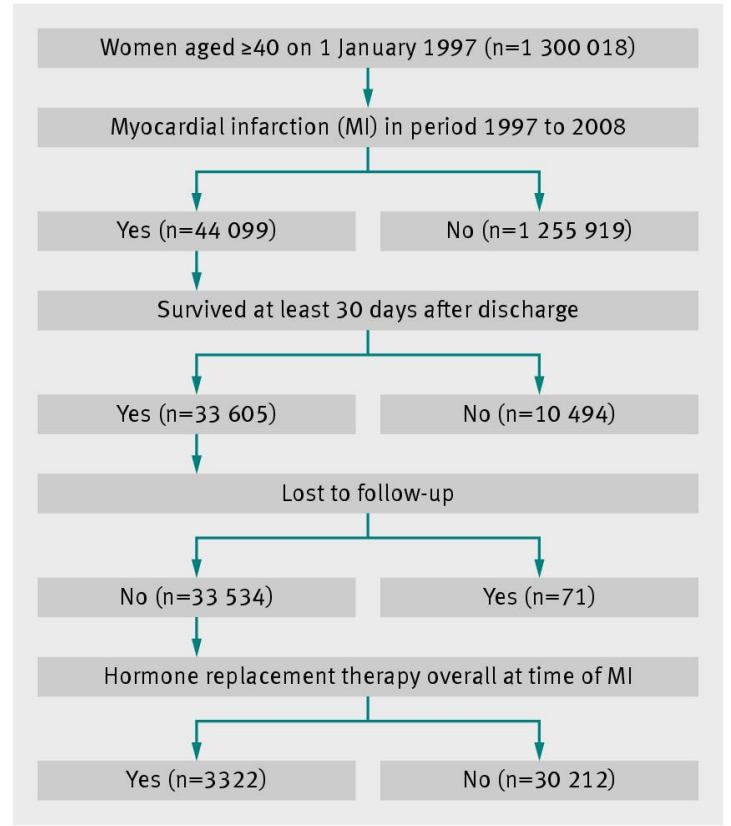

Fig 1 Study population

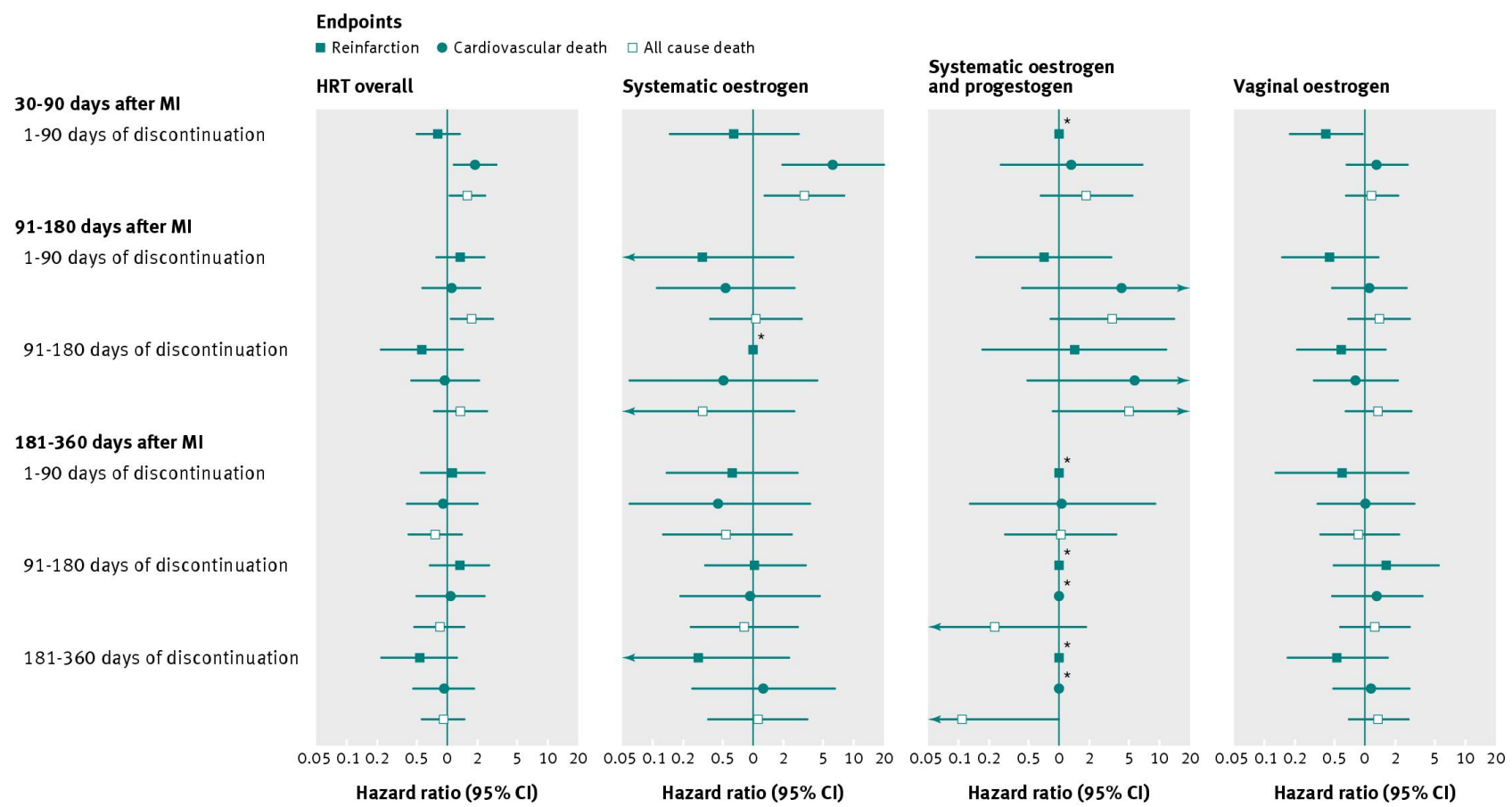

Fig 2 Hazard ratios $(95 \% \mathrm{Cl})$ for reinfarction, cardiovascular mortality, and all cause mortality for discontinuation of hormone replacement therapy (HRT) overall and HRT categories. Hazard ratios are for discontinuation with continued use as reference. Multivariable Cox proportional hazards analysis was adjusted for age group, year of myocardial infarction (MI), comorbidity (previous MI, revascularisation within 30 days of $\mathrm{MI}$, cerebrovascular disease, congestive heart failure, malignancy, cardiac dysrhythmias, chronic renal failure, acute renal failure, diabetes with complications, pulmonary oedema, shock), concomitant drug use ( $\beta$ blockers, angiotensin converting enzyme inhibitors, statins, loop diuretics, clopidogrel, glucose lowering drugs), and income. No interactions were found or included in model 


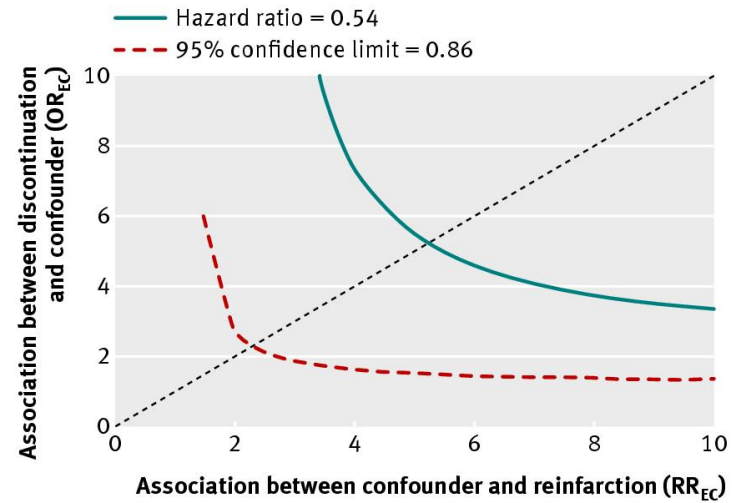

Fig 3 Required size of unmeasured confounder to fully explain decrease in risk from 1.00 to 0.54 (solid blue line) and to render results statistically insignificant (dashed red line), assuming prevalence of confounder of $20 \%$ in population and prevalence of discontinuation of $20 \%$

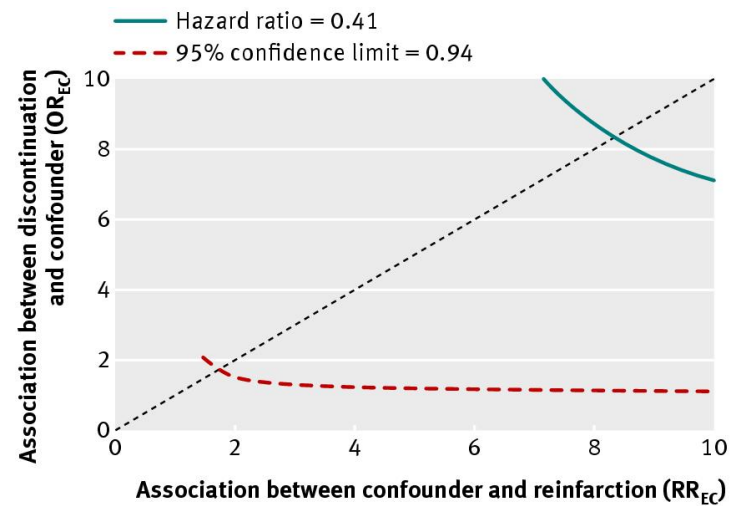

Fig 4 Required size of unmeasured confounder to fully explain decrease in risk from 1.00 to 0.41 (solid blue line) and to render results statistically insignificant (dashed red line), assuming prevalence of confounder of $20 \%$ in population and prevalence of discontinuation of $20 \%$ 